A - Research concept and design

B - Collection and/or assembly of data

$\mathrm{C}$ - Data analysis and interpretation

D - Writing the article

E - Critical revision of the article

F - Final approval of article

Received: 2021-09-19

Accepted: 2021-11-20

Published: 2021-11-24

\section{Can a cervical muscle inhibition technique reduce chronic low back pain?}

\author{
Shabnam Joshi ${ }^{\mathrm{A}, \mathrm{E}-\mathrm{F}}$ (D), Rekha Yadav ${ }^{\mathrm{B}-\mathrm{E}}$ (D), Alka Pawalia*A,C-F (D) \\ Department of Physiotherapy, Guru Jambheshwar University of Science \& \\ Technology, Hisar, India
}

*Correspondence: Alka Pawalia, Department of Physiotherapy, Guru Jabheshwar University of Science \& Technology, Hisar, India; email: alkapawalia@gmail.com

\title{
Abstract
}

Introduction: Chronic low back pain is the pain in the lumbo-sacral area with a duration of more than 3 months. The aim of the study was to find out the efficacy of sub-occipital muscle inhibition technique along with interferential therapy and exercises on pain and other functional parameters in chronic low back pain patients.

Material and methods: 45 patients with a mean age of $38.53 \pm 9.36$ years who had chronic low back pain were randomly assigned to 3 groups ( $\mathrm{n}=15$ in each group). Group-A received sub-occipital muscle inhibition technique, interferential therapy and exercise training, Group-B received interferential therapy and exercise training and Group-C received exercise training only for 3 days/week for 4 weeks. The outcome measures used were Numerical Pain Rating Scale, Modified-Modified Schober's Test, Oswestry Disability Index and SF-36 questionnaire. Patients were assessed at baseline, after 2 weeks and 4 weeks.

Results: There was significant within-group-effects $(\mathrm{p}=0.001)$ for NPRS, lumbar flexion, functional disability (ODI) and quality of life (SF-36) in all the three groups, but not Lumbar extension. There was significant between-group-effect in lumbar flexion, lumbar extension and functional disability $(\mathrm{p}<0.05)$.

Conclusions: The sub-occipital muscle inhibition technique along with interferential therapy and spinal exercises have better clinical effects than interferential therapy and exercises alone in chronic low back pain patients.

\section{Keywords: interferential therapy, low back pain, sub-occipital muscle, muscle inhibition technique}

\section{Introduction}

The chronic mechanical low back pain is the pain in the lumbo-sacral area (from L1-S1 vertebra) with a duration of more than three months and is not associated with any other pathology, like tumor, infection, spinal fracture, radicular syndrome and other inflammatory disorders [1]. The low back pain occurs mostly at lumbar segments i.e. L4-L5 and it is the major cause of disability worldwide [2]. The chronic non-specific low back pain is mechanical in origin which includes muscle strains, disc disorders and sacro-iliac joint dysfunctions [2]. There are various mechanical and psychological factors like heavy weight lifting or vigorous

This is an Open Access journal, all articles are distributed under the terms of the Creative Commons Attribution-NonCommercial-ShareAlike 4.0 International (CC BY-NC-SA 4.0). License (http://creativecommons. org/licenses/by-nc-sa/4.0/). 
exercise, awkward posture, sedentary lifestyle and being overweight can lead to low back pain $[1,3,4]$. The weak abdominal muscles and tightness of hamstring, glutei muscles can also lead to low back ache [5]. The hamstring is the muscle which often gets tight and its flexibility is important for the normal lumbar spine mechanics $[2,6]$. The tight hamstring produces negative impact on the pelvic region, reduces lordotic curve and alters the lumbo-pelvic rhythm [7].

Chronic low back pain produces a debilitating effect on patients life which leads to disability and reduces their ability to perform daily living activities [8]. There is unknown cause for around $85 \%$ of back pain issues that can be diagnosed by X-ray and magnetic resonance imaging [9]. Hence, it is important to understand the cause of back pain, so that it can be removed from the patients life. There are various physical therapy techniques which can be used for treating chronic low back pain such as exercise therapy, massage, manipulations, mobilizations and by using modalities like Transcutaneous Electrical Nerve Stimulation, Light Amplification by Stimulated Emission of Radiation, Interferential Therapy (IFT) etc. However, the appropriate intervention for chronic mechanical low back pain remains elusive [10].

The interferential therapy is one of the usual mode of physical therapy treatment for back pain. The interferential therapy is a medium frequency alternating current, with amplitude-modulation at a low frequency. The IFT consists of two medium frequency currents, that passes simultaneously through the tissues, where both the currents cross their paths and interference occurs at that point. It helps in decreasing pain, enhance circulation and has a counter-irritant effect. It is used effectively because its penetration in the skin is deep, with minor discomfort. Some of the studies proved that interferential therapy was effective in decreasing pain, increasing lumbar spine mobility, reducing functional limitations and improving quality of life in chronic low back pain patients [11-14].

Another method is spinal exercises which consists of stretching and strengthening exercises. There are various types of spinal exercises that are used to treat chronic low back pain (CLBP), such as hamstring stretching, back muscles stretching, core stabilization exercise and strengthening exercises for low back muscles $[5,15]$. In CLBP patients, there is restriction in trunk movements, decreases core strength and increases lumbar instability which results in low back pain [16]. So, the abdominal muscles strengthening is vital in reducing low back pain as they support the lumbar spine and the lumbar stabilization exercises train the muscular motor patterns that helps in increasing the spinal stability which reduces low back pain [15]. Strengthening exercises are the efficient and appropriate intervention for gaining functional movements and completing activities of daily living [9]. Hence, all the exercises show different results in reducing low back pain [9]. However, these methods are the usual modes of physical therapy intervention for chronic low back pain, so other treatment techniques should be incorporated for treating the chronic low back pain.

The sub-occipital muscle inhibition technique is one of the newest approach for the treatment of back pain. This is a manual technique which helps in relaxation of the sub-occipital muscles by reducing myofascial restriction in the sub-occipital region. It helps in improving head and neck movements by putting light pressure to the tender points in the occipital muscles when the patient lies comfortably in supine position. The suboccipital muscle inhibition technique reduces sub-occipital muscle tension which helps in myo-fascial relaxation which can further helps in increasing hamstring flexibility because these are connected by superficial back line [17].

The superficial back line is a fascial tract which connect various sections of the body to one another which consists of the epi-cranial fascia, erector spinae cords, sacro-tuberous ligament, hamstrings, triceps surae and plantar fascia [7]. So, tightness or tender points in one or more muscles of the fascial tract can affect the movement of other joints which are included in the similar fascial tract. In the same way, the hamstring muscle is connected with the sub-occipital muscles through dura mater by the superficial back line. Hence, the trigger points or tightness in sub-occipital muscles may disrupt the function of hamstring muscle and tightness of hamstring muscle may be a contributing factor for development of low back pain.

So, application of sub-occipital muscle inhibition technique may be beneficial in increasing hamstring extensibility which can further helps in reducing low back pain, increasing lumbar spine mobility and reducing functional limitations. Moreover, the sub-occipital muscle inhibition technique has been reported to be beneficial in reducing pain, increasing hamstring extensibility and reducing functional disability in hamstring tightness and chronic low back pain patients $[2,6,7,17,18]$. However, the sub-occipital muscle inhibition technique has been found to be effective for the treatment of cervical spine disorders $[19,20]$ but its effect on other structures like lower back has not been explored yet. So, the purpose of the present study is to investigate the effect of sub-occipital muscle inhibition technique along with interferential therapy and exercises on pain, lumbar spine mobility, functional disability and in quality of life in chronic low back pain patients. 


\section{Materials and methods}

A randomized, controlled and single blinded (participant) clinical trial was carried out. Ethical approval was taken from Institutional Ethical Committee, vide letter no PTY/2021/42, Department of Physiotherapy, Guru Jambheshwar University of Science and Technology, Hisar. The CTRI registration number for this trial is CTRI/2021/07/035198. Informed consent was taken from each participant before including in the study. Using convenience sampling technique, the participants with chronic low back pain with duration of more than 3 months were recruited from Physiotherapy OPD in GJUS\&T, Hisar. The sample size was 45 participants calculated by using $\mathrm{G}^{*}$ power software version 3.1.9.4 in which the effect size was taken as 1.63 and statistical power was 0.95 with a significance value set to 0.05 . The following inclusion criteria were used for selection of patients: age between 20-60 years, both females and males were included with chronic mechanical low back pain of more than 3 months, without pain radiation to lower extremities and positive slump test. Patients were excluded if they had any of the following conditions: tumors, skin infections, spinal fracture, cauda equina syndrome, pregnant patients, patients with previous lumbar surgery, psychologically unstable patients and uncooperative patients. The mean age for the study participants was $38.53 \pm 9.36$ years, mean height was $1.67 \pm 0.05$ meters, mean weight was $65.44 \pm 10.11 \mathrm{~kg}$ and mean BMI was $23.59 \pm 3.31 \mathrm{~kg} / \mathrm{m}^{2}$.

Table 1 showing demographic characteristics of patients concerning age, body weight, height and body mass index. These findings were not statistically significant with $\mathrm{p}>0.05$ (Table 1 ).

\section{Procedure}

The screening of 56 participants was done and 45 participants fulfilled the inclusion criteria were selected for the study as shown in flow diagram (figure 1). They were randomly divided into 3 groups i.e. Group A, B and C. Each group consisted of 15 participants. Initially, the demographic data of all the participants was obtained such as age (years), height (metres), weight (kilograms) and body mass index $\left(\mathrm{kg} / \mathrm{m}^{2}\right)$. All the measurements were taken at baseline, at two weeks and four weeks.

The Numerical Pain Rating Scale is used for measuring pain intensity in which patients were asked to rate their pain on 11-point numerical scale [17]. The scale consists of 0 to 10 points in which " 0 " determines "no pain at all" and "10" determines "worst possible pain".

Lumbar spine mobility was assessed using the Modified-Modified Schober's Test. This test is a valid and reliable method for the measurement of lumbar movements [21]. The patient was in standing position and by standing behind the patient thumbs were placed on the patients PSIS (posterior superior iliac spine) level and a horizontal mark (first line) was made along the midline of lumbar spine at the PSIS level i.e. lower landmark. Then, second line was marked, $15 \mathrm{~cm}$ above the first line i.e. higher landmark. Then, the patient bends forward (trunk flexion) but not beyond the level of increasing pain. Now, the new distance during the flexion movement was measured in between the lower (first line) and higher (second line) markings. Then, the patient returned to the standing position. The difference between the marking points in the standing position and in the flexion position was used as the range of lumbar flexion. The same markings were used for measuring lumbar extension and the patient did extension or backward bending in lumbar extension movement and the difference between the neutral and lumbar extension movements was measured in centimeters.

Functional disability was assessed by using the Oswestry Disability Index questionnaire. The Oswestry Disability Index questionnaire is a valid and reliable tool that gives score in percentage [22]. It is the most widely used scale for determining the functional disability caused by low back pain.

Quality of Life was assessed by using SF-36 Questionnaire. The SF-36 scale is a reliable and valid tool for measuring quality of life in chronic pain patients [23]. The SF-36 scale is a 36 -item self-administered scale which is used to measure overall health functions in eight domains.

Tab. 1. Demographic characteristics of participants

\begin{tabular}{lccccc}
\hline Characteristics & $\begin{array}{c}\text { Group-A } \\
\text { Mean } \pm \text { SD }\end{array}$ & $\begin{array}{c}\text { Group-B } \\
\text { Mean } \pm \text { SD }\end{array}$ & $\begin{array}{c}\text { Group-C } \\
\text { Mean } \pm \text { SD }\end{array}$ & F-Ratio & p-value \\
\hline Age $($ years $)$ & $34.93 \pm 9.43$ & $42.47 \pm 10.15$ & $38.20 \pm 7.27$ & 2.622 & 0.085 \\
Height $(\mathrm{m})$ & $1.66 \pm 0.04$ & $1.65 \pm 0.06$ & $1.68 \pm 0.05$ & 1.267 & 0.292 \\
Weight $(\mathrm{kg})$ & $62.00 \pm 8.50$ & $67.20 \pm 12.43$ & $67.13 \pm 8.67$ & 1.326 & 0.276 \\
BMI $\left(\mathrm{kg} / \mathrm{m}^{2}\right)$ & $22.48 \pm 2.79$ & $24.56 \pm 4.10$ & $23.72 \pm 2.75$ & 1.527 & 0.229 \\
\hline
\end{tabular}




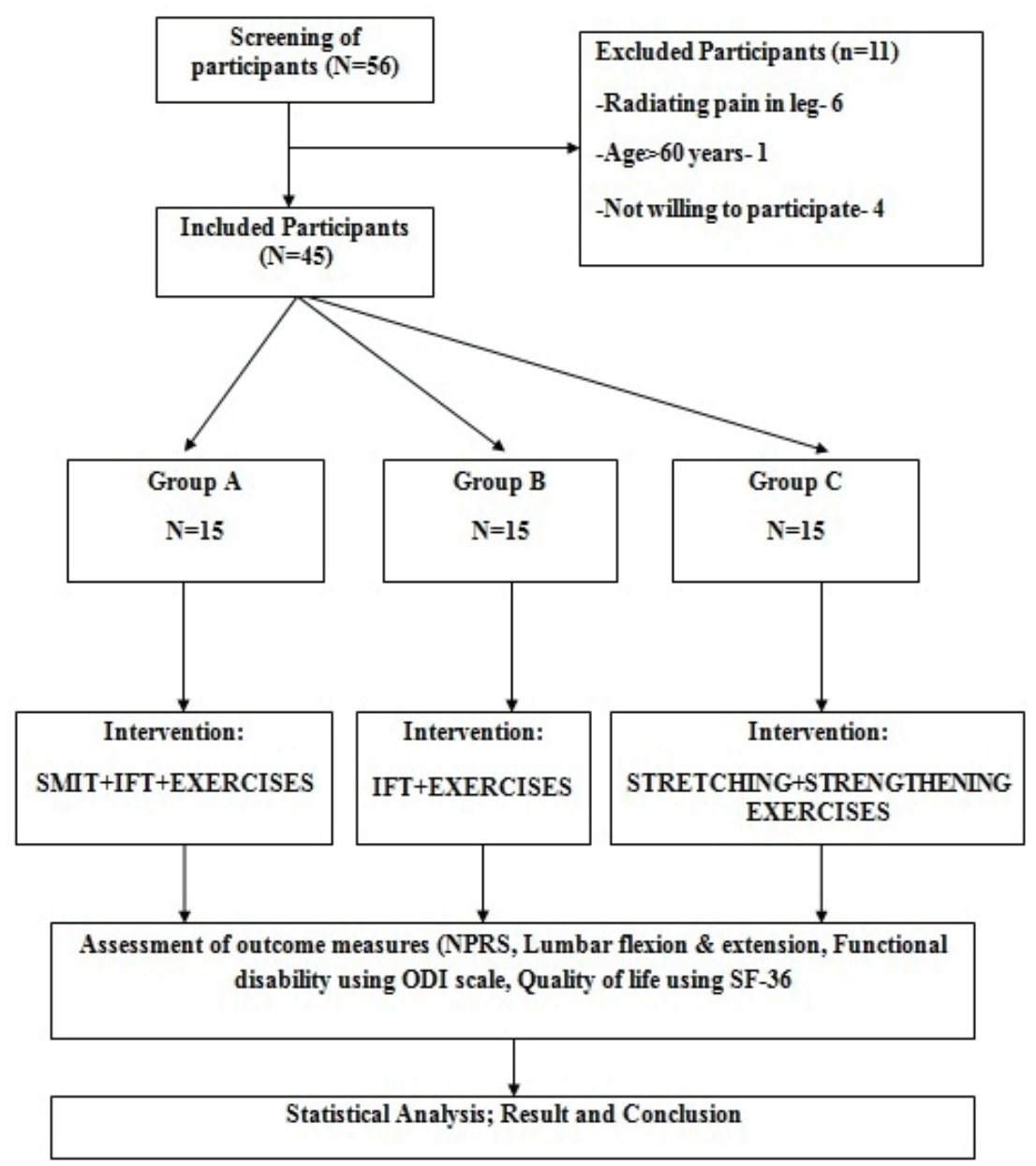

Fig. 1. The flow diagram for the study

\section{Intervention}

The participants of Group A were treated with 3 repetitions of sub-occipital muscle inhibition technique, Interferential current therapy was given for 30 minutes and also performed 10 repetitions for each stretching and strengthening exercises. Hot water fomentation (HWF) was given for 10 minutes. The stretching exercises included were: a). Hamstring stretching b). Single knee to chest stretching. The strengthening exercises included were: a). Abdominal curl-up exercise b). Trunk extension exercises. Group B received IFT for 30 minutes and performed 10 repetitions of each stretching and strengthening exercises. HWF was given for 10 minutes. Group $\mathrm{C}$ was treated with HWF for 10 minutes and performed 10 repetitions of each stretching and strengthening exercises. The intervention to all the 3 groups was given 3 times/week for a duration of 4 weeks.

Sub-Occipital Muscle Inhibition Technique: The patient was lying comfortably in supine position and his/ her eyes were closed during the treatment to avoid any eye motions that can affect the sub-occipital muscle tone. While sitting towards the head end of the couch, the technique was applied by placing the palm of the hands below the patient's head and finger pads on the occipital region. Then, the pressure was applied upward and towards the eyeball and held for at least two minutes until the tissues were relaxed, as similar to other studies $[2,6]$. The technique was performed three times with ten seconds rest in between the repetitions.

Interferential Therapy: First, the patient was positioned comfortably in prone lying. The area to be treated was exposed, checked for any scars or redness and then, cleaned with water. The four electrodes were placed in a quadric-polar technique over the affected area (lower back) of the patient. The patient was informed that he/ she will feel a tingling sensation which should not be too uncomfortable. The program 029 was selected for low back pain and the parameters were already set in interferential unit (Beat Frequency: $-150 \mathrm{~Hz}$ ). Then, the interferential current was gradually increased, according to the patient's tolerance, with comfortable tingling sensation. The interferential current therapy was applied for 30 minutes per session for 3 days/week for 4 weeks. 
Strengthening exercises: Abdominal curl up: - i) The patient was lying in supine position. Then, the patient was asked to come to sitting position with the hips and knees flexed, lift the head and shoulders with a gradual curl to touch the knees with the hands. The patient held this position for five to ten seconds and then again returned to starting position. Ten repetitions of the same movement were performed by the patients. ii) Trunk extension exercise: - The patient was made to lie in prone position, with both the hands on the sides and the head in neutral position without any rotation to either side. Then, the patient was asked to lift the head and shoulders as much as possible and hold the position for ten seconds, then relax for next ten seconds. The ten repetitions of the same movement were performed by the patients.

Stretching exercises:

- Hamstring stretching exercise: the patient was lying in supine position and hip flexion of $90^{\circ}$ was done on one leg and the other leg was placed in extension. The flexed leg of the patient was then straightened (knee extension) while maintaining hip flexion at $90^{\circ}$ as much as possible and the ankle in dorsiflexion position. The patient held this position for ten seconds and the same movement was repeated with each leg ten times per session with both legs.

- Single knee to chest stretch: the patient was made to lie in supine position. Then, the patient was asked to hold one of the knee to the chest while maintaining other leg in extension. Then, the patient returned to the starting position. The same movement was repeated by the patient with the other leg. The patient held this position for ten seconds and same movement was repeated by the patient with each leg ten times per session.

\section{Statistical analysis}

The statistical analysis was done by using the SPSS (IBM statistical package for social science) software version 21. Mean, standard deviation, F-ratio and pvalue were calculated for all the outcome measures. The between group and within group comparisons were made by using ANOVA (Analysis of Variance) test. The level of significance ( $p$-value) was taken as $<0.05$. Further, Post hoc analysis was done to find for between group differences if results showed significant differences between groups. The post hoc analysis test used for the study was Tukey HSD.

\section{Results}

On assessing the study participants anthropometric data, the study showed that at baseline all the three treatment groups were comparable i.e. there were no statistical significant differences between them when the study was initiated as already shown in table 1 . On comparing the various study parameters within treatment groups for pre and post comparisons, there was significant improvement seen for majority of study parameters in all the three groups. however, this was not seen for lumbar extension ROM for group B and group $\mathrm{C}$, though there was clinical improvement in ROM but was not statistically significant enough with $\mathrm{p}$ values at 0.552 and 0.567 for group $\mathrm{B}$ and group C respectively. However, when we did the between group comparisons for three treatments, the lumbar extension was significant between groups $(p=0.009)$ along with lumbar flexion and disability scores $(p=0.001$ and $p=$ 0.006). When post hoc analysis was done for the above significant findings, both SMIT and IFT were found to be significantly better than only the exercises to improve lumbar flexion ROM ( $\mathrm{p}=0.001 \& \mathrm{p}=0.012)$. While for improving lumbar extension ROM, only SMIT group was significantly better than both IFT and exercise group $(p=0.008 \& p=0.081)$, and for disability only SMIT group was significantly better than exercise group $(p=0.005)$. This shows the benefits of SMIT over IFT and exercises when given alone in treating chronic low back pain.

Sub-occipital muscle inhibition technique along with the interferential therapy and exercises was effective and Group-A (SMIT, IFT and exercises) showed significant improvement in all the dependent variables as compared to Group-B (IFT and exercises) and C (only exercises) that supports the alternate hypothesis. Thus, it was concluded from within-subject-effect that all the treatments were effective in reducing pain, increasing lumbar flexion, decreasing functional disability and improving quality of life, but does not show much improvement in increasing lumbar extension. Regarding between-subject-effect, ANOVA test shows that there was significant $(\mathrm{p}<0.05)$ increase in lumbar flexion and extension and significant decrease was seen in functional disability $(\mathrm{p}<0.05)$, but significant difference was not seen on pain and in quality of life ( $p>$ $0.05)$.

Table 2 showing the outcome variables (NPRS, lumbar flexion, lumbar extension and functional disability) at baseline, which were not statistically significant ( $p>0.05)$, but SF-36 was found to be statistically significant at baseline $(\mathrm{p}<0.05)$ (Table 2$)$.

Table 3 showing the within group comparisons for numerical pain rating scale, lumbar flexion, functional disability and quality of life in the groups. ANOVA test reveals that there were significant findings within group $(\mathrm{p}=0.000)$ for numerical pain rating scale, lumbar flexion, functional disability and quality of life in all the three groups. The lumbar extension was significant 
Tab. 2. Baseline data scores for various study outcomes in three groups

\begin{tabular}{lccccc}
\hline Variables & $\begin{array}{c}\text { Group-A } \\
\text { Mean } \pm \text { SD }\end{array}$ & $\begin{array}{c}\text { Group-B } \\
\text { Mean } \pm \text { SD }\end{array}$ & $\begin{array}{c}\text { Group-C } \\
\text { Mean } \pm \text { SD }\end{array}$ & F-Ratio & p-value \\
\hline Numerical pain rating & $5.53 \pm 0.92$ & $5.93 \pm 0.70$ & $5.53 \pm 0.92$ & 1.105 & 0.341 \\
scale & $4.95 \pm 0.41$ & $4.95 \pm 0.29$ & $5.07 \pm 0.25$ & 0.659 & 0.523 \\
Lumbar Flexion & $1.23 \pm 0.35$ & $1.29 \pm 0.35$ & $1.30 \pm 0.42$ & 0.166 & 0.848 \\
Lumbar Extension & $30.90 \pm 11.16$ & $30.31 \pm 9.95$ & $23.99 \pm 7.74$ & 2.323 & 0.110 \\
Oswestry Disability Index & $58.45 \pm 10.51$ & $48.91 \pm 10.76$ & $56.70 \pm 10.86$ & 3.373 & $0.044^{*}$ \\
Short Form-36 scale & & & &
\end{tabular}

* Significant at $95 \%$ confidence interval (CI).

Tab. 3. Various study parameters at different time points in each group for study

\begin{tabular}{|c|c|c|c|c|c|c|c|}
\hline \multirow{2}{*}{ Variables } & \multirow{2}{*}{ Duration } & \multicolumn{2}{|c|}{ Group-A } & \multicolumn{2}{|c|}{ Group-B } & \multicolumn{2}{|c|}{ Group-C } \\
\hline & & Mean \pm SD & $\mathrm{p}$ & Mean \pm SD & $\mathrm{p}$ & Mean \pm SD & $\mathrm{p}$ \\
\hline \multirow{3}{*}{ NPRS } & Baseline & $5.53 \pm 0.92$ & \multirow{3}{*}{$0.001 *$} & $5.93 \pm 0.70$ & \multirow{3}{*}{$0.001 *$} & $5.53 \pm 0.92$ & \multirow{3}{*}{$0.001 *$} \\
\hline & 2 Weeks & $2.40 \pm 0.74$ & & $2.47 \pm 0.83$ & & $3.00 \pm 0.65$ & \\
\hline & 4 Weeks & $0.23 \pm 0.44$ & & $0.30 \pm 0.63$ & & $0.77 \pm 0.73$ & \\
\hline \multirow{3}{*}{$\begin{array}{l}\text { Lumbar } \\
\text { Flexion }\end{array}$} & Baseline & $4.95 \pm 0.41$ & \multirow{3}{*}{$0.001 *$} & $4.95 \pm 0.29$ & \multirow{3}{*}{$0.001 *$} & $5.07 \pm 0.25$ & \multirow{3}{*}{$0.001 *$} \\
\hline & 2 Weeks & $5.40 \pm 0.29$ & & $5.33 \pm 0.30$ & & $5.40 \pm 0.23$ & \\
\hline & 4 Weeks & $5.76 \pm 0.29$ & & $5.60 \pm 0.25$ & & $5.45 \pm 0.21$ & \\
\hline \multirow{3}{*}{$\begin{array}{l}\text { Lumbar } \\
\text { Extension }\end{array}$} & Baseline & $1.23 \pm 0.35$ & \multirow{3}{*}{$0.046^{*}$} & $1.29 \pm 0.35$ & \multirow{3}{*}{0.552} & $1.30 \pm 0.42$ & \multirow{3}{*}{0.567} \\
\hline & 2 Weeks & $1.37 \pm 0.28$ & & $1.35 \pm 0.32$ & & $1.41 \pm 0.34$ & \\
\hline & 4 Weeks & $1.52 \pm 0.25$ & & $1.42 \pm 0.31$ & & $1.44 \pm 0.34$ & \\
\hline \multirow{3}{*}{ ODI } & Baseline & $30.90 \pm 11.16$ & \multirow{3}{*}{$0.001 *$} & $30.31 \pm 9.95$ & \multirow{3}{*}{$0.001 *$} & $23.99 \pm 7.74$ & \multirow{3}{*}{$0.001 *$} \\
\hline & 2 Weeks & $14.03 \pm 6.40$ & & $14.37 \pm 6.46$ & & $13.64 \pm 5.43$ & \\
\hline & 4 Weeks & $3.54 \pm 4.73$ & & $5.83 \pm 4.37$ & & $5.70 \pm 3.45$ & \\
\hline \multirow{3}{*}{ SF-36 } & Baseline & $58.45 \pm 10.51$ & \multirow{3}{*}{$0.001 *$} & $48.91 \pm 10.76$ & \multirow{3}{*}{$0.001 *$} & $56.70 \pm 10.86$ & \multirow{3}{*}{$0.006^{*}$} \\
\hline & 2 Weeks & $73.48 \pm 11.95$ & & $66.04 \pm 8.60$ & & $66.44 \pm 11.92$ & \\
\hline & 4 Weeks & $77.97 \pm 9.94$ & & $69.76 \pm 8.65$ & & $70.29 \pm 9.91$ & \\
\hline
\end{tabular}

* Significant at $95 \%$ confidence interval (CI).

Tab. 4. Showing between group comparison scores for all the outcome measures

\begin{tabular}{lccccc}
\hline Variables & Group-A & Group-B & Group-C & F-Ratio & p-value \\
\hline Numerical pain rating scale & $4.93 \pm 1.16$ & $5.27 \pm 0.88$ & $4.53 \pm 1.19$ & 1.712 & 0.193 \\
Lumbar Flexion & $0.73 \pm 0.22$ & $0.64 \pm 0.25$ & $0.41 \pm 0.13$ & 9.251 & $0.001^{*}$ \\
Lumbar Extension & $0.25 \pm 0.16$ & $0.10 \pm 0.10$ & $0.15 \pm 0.13$ & 5.298 & $0.009 *$ \\
Oswestry Disability Index & $-26.21 \pm 7.43$ & $-23.33 \pm 9.37$ & $-16.99 \pm 5.58$ & 5.742 & $0.006^{*}$ \\
Short Form-36 scale & $18.61 \pm 5.88$ & $20.40 \pm 10.23$ & $13.68 \pm 7.91$ & 2.709 & 0.078 \\
\hline
\end{tabular}

* Significant at $95 \%$ confidence interval (CI). 
within Group-A ( $\mathrm{p}=0.046)$, but it was not statistically significant within Group-B $(\mathrm{p}=0.552)$ and Group-C $(\mathrm{p}=0.567)$ (Table 3$)$.

Table 4 showing the between group comparison for lumbar flexion, lumbar extension and functional disability, which were significant $(p<0.05)$, but comparison for pain and quality of life between groups shows no statistical significant change ( $p>0.05)$ (Table 4).

\section{Discussion}

The aim of the study was to assess the effectiveness of a four-weeks treatment programme of suboccipital muscle inhibition technique along with the interferential therapy and exercises on pain and other functional parameters in chronic low back pain patients. To the best of our knowledge, this is the first study that investigated the effects of the sub-occipital muscle inhibition technique along with interferential therapy and exercises on pain and other functional parameters in patients with chronic low back pain. Most studies done with sub-occipital muscle inhibition technique have focused mainly on cervical spine treatment $[19,20]$. Few studies have explored its effect on hamstring flexibility $[6,7,17,18]$ and only one study reports the effect of sub-occipital muscle inhibition technique in chronic low back pain patients, but with some limitations [2].

The main findings of this randomized controlled trial was that a four-weeks treatment of sub-occipital muscle inhibition technique along with interferential therapy and exercises significantly increases lumbar flexion and extension, decreases pain, reduces functional disability and also improves quality of life in chronic lower back pain patients. It might be due to the fact that there is anatomical attachment of lumbar spine with the dura matter and if some changes occurred in lumbar spine mechanics, then the dural tension was also affected which can lead to low back pain [24]. The sub-occipital muscle inhibition technique reduces the dural tension which increases lumbar spine mobility and decreases low back pain [24]. The sub-occipital muscle inhibition technique provides muscular relaxation through the activation of Autonomic Nervous System and causes the release of $\beta$-endorphins that reduces the pain perception [2]. The improvement in lumbar ROM occurred may be due to increase in hamstring extensibility and good hamstring extensibility allows greater ROM to occur at the hip and pelvis region, which reduces lumbar spine bearing stress $[6,17]$. This may reduce the functional limitations and allows the easier performance of daily living activities which are limited due to pain in lower back [24]. Regarding sub-occipital muscle inhibition technique, the results of the present study are similar to another study which found that sub-occipital muscle inhibition technique decreases pain and increases lumbar spine mobility in chronic mechanical low back pain patients [2]. In addition, another study concluded that five sessions of sub-occipital muscle inhibition technique helps in reducing the tightness of hamstring muscle in healthy population, reduces functional disability and improve their well-being [6]. Thus concluded that suboccipital muscle inhibition technique along with exercises have better clinical effect as compared to exercise group alone in chronic LBP patients.

In addition, the interferential current penetrates deeper into the tissues that leads to significant and longterm pain reduction, and also improves functional ability. According to Tantawy et al., 2020, the interferential current therapy helps in reduction of pain at rest and activity, and shows a marked increase in back range of motion. It concluded that interferential stimulation was better in pain modulation. The interferential therapy produces analgesic effect by the Wedensky inhibition of Type-C nociceptive fibers. The interferential therapy excites the $\mathrm{A} \beta$ fibers, and blocks the pain information carried by $\mathrm{C}$-fibers to the dorsal horn of the spinal cord and hence, the pain perception was reduced [12]. The present study was supported by a study done on the effect of the interferential therapy in chronic low back pain patients in which interferential therapy was given for 30 minutes and three days per week for four weeks [14].

The exercise increases tissue blood flow and facilitates the healing process by supplying nutrients and oxygen to the affected region. The exercises also help in removing irritable and waste substances from the affected region, that leads to reduction in lower back pain [9]. The stretching and strengthening exercises reduces lumbar lordosis and improves spinal stability by producing a self-made corset and also reduced the fear of movement, which may be a cause for functional limitation [9]. Moon et al. [25] concluded that the lumbar strengthening exercises decreases the lower back pain. Lumbar stabilization exercises and walking have also been shown to improve pain and muscle endurance in chronic low back pain [26]. Seif et al. also [5] concluded that hamstring and back muscles stretching and abdominal muscle strengthening exercises improves lumbar range of motion in chronic low back pain patients. Sub occipital muscle inhibition technique have also been shown to improve hamstrings flexibility [27]. This is because the tone of the sub occipital muscles effects the tone of the hamstring muscles too due to their connections of the myofascia [24] as these two regions are connected by one neural system passing through dura mater called as superficial back line [28,29]. 
The high percentage of improvement in pain and other functional parameters were in favor of sub-occipital muscle inhibition technique along with interferential therapy and exercises group (Group-A) as compared to other two groups (Group-B and C) that supports the alternate hypothesis and rejects the null hypothesis. Moreover, the interferential therapy along with exercises was found to be more effective as compared to the only exercise group in reducing pain, increasing lumbar spine mobility, reducing functional disability and also in improving quality of life in chronic lower back pain patients. So, the current study along with the above mentioned studies provided new approach for treating the chronic low back pain and encouraged future researchers to carry out the remote effects of cervical treatment that can help in treating spinal and lower limb musculoskeletal diseases.

\section{Conclusion}

Through this study it is concluded that the sub-occipital muscle inhibition technique along with interferential therapy application and exercises was more effective in reducing pain, increasing lumbar spine mobility, reducing functional disability and in improving quality of life in chronic low back pain patients as compared to only interferential therapy or exercises given alone. All the three treatment techniques were effective in reducing pain and functional disability and improving quality of life along with spinal mobility. Though, all individual treatment techniques were equally effective in reducing pain and improving quality of life but none of them were better than the rest. While for improving spine mobility and reducing disability in individuals suffering with chronic low back pain adding SMIT can be beneficial than interferential therapy or exercises given alone.

\section{References}

1. Balague F, Mannion AF, Pellise F, Cedraschi C. Nonspecific low back pain. The Lancet. 2012; 379(9814): 482-91.

2. Hasaneen BH, Eweda RS, Balbaa AE. Effects of the sub-occipital muscle inhibition technique on pain intensity, ROM and functional disability in patients with chronic mechanical low back pain. Bull Fac Phys Ther. 2018; 23(1): 15-21.

3. Hartvigsen J, Hancock MJ, Kongsted A, Louw Q et al. What low back pain is and why we need to pay attention. The Lancet. 2018; 391(10137): 2356-67.

4. O'Sullivan PB, Caneiro JP, O'Sullivan K, Lin I, Bunzli S et.al. Back to basics: 10 facts every person should know about back pain. Br J Sports Med. 2019; 54(12): 698-9.

5. Seif HE, Alenazi A, Hassan SM, Kachanathu SJ, Hafez AR. The Effect of Stretching Hamstring, Gastrocnemius, Iliopsoas and Back Muscles on Pain and Functional Activities in Patients with Chronic Low Back Pain: A Randomized Clinical Trial. Open J Ther Rehabil. 2015; 3(4): 139-45.

6. Jagtap PK, Mandale SD. The Effect of Sub-Occipital Muscle Inhibition Technique on Hamstring Tightness Patients. J Evol Med and Dent Sci. 2015; 4(33): 5682-9.

7. Cho SH, Kim SH, Park DJ. The comparison of the immediate effects of application of the sub-occipital muscle inhibition and self-myofascial release techniques in the sub-occipital region on short hamstring. J Phys Ther Sci. 2015; 27(1): 195-7.

8. Smith, JA, Osborn M. Pain as an assault on the self: An interpretative phenomenological analysis of the psychological impact of chronic benign low back pain. Psychol Health. 2007; 22(1): 517-34.

9. Gordon R and Bloxham S. A systematic review of the effects of of exercise and physical activity on non-specific chronic low back pain. Healthcare (Basel). 2016; 22(4): 1-19.

10. Mayer J, Mooney V, Dagenais S. Evidence-informed management of chronic low back pain with lumbar extensor strengthening exercises. Spine J. 2008; 8(1): 96-113.

11. Cabello MA, Martin JM, Maldonado GD, et al. Effect of interferential current therapy on pain perception and disability level in subjects with chronic low back pain: A randomized controlled trial. Clin Rehabil. 2017; 31(2): 242-9.

12. Jung KS, Sung T. Effects of interferential current treatment on pain, disability and balance in patients with chronic low back pain: A Randomized controlled study. J Korean Soc Phys Med. 2020; 15(3): 21-7.

13. Olawale OA and Agudzeamegah CM. The efficacy of interferential therapy and exercise therapy in the treatment of low back pain. Niger J Exp Clin Biosci. 2014; 2(1): 10-4.

14. Tantawy SA, Kamel DM, Abdelbasset WK, Nambi G. A randomized controlled trial investigating the impact of interferential therapy on pain, range of motion and quality of life in patients with chronic non-specific low back pain. Arch Balk Med Union. 2020; 55(1): 47-54.

15. Franca FR, Burke TN, Hanada ES, Marques AP. Effects of muscular stretching and segmental stabilization on functional disability and pain in patients with chronic low back pain. J Manipulative Physiol Ther. 2012; 35(4): 279-85.

16. Danneels LA, Vanderstraeten GG, Cambier DC, et al. $\mathrm{CT}$ imaging of trunk muscles in chronic low back pain 
patients and healthy control subjects. Eur Spine J. 2000; 9(1): 266-72.

17. Panse R, Yeole U, Trivedi S, Pawar P. To study the effect of Sub-Occipital Muscle Inhibition and Neural Flossing Techniques on Hamstring Flexibility in Young Adults. J Med Sci Clin Res. 2018; 06(11): 846-51.

18. Desai B, Foram B, Shreeya V, et al. A study to compare retro-walking and sub-occipital muscle inhibition technique in hamstring muscle flexibility in collegiate students: An experimental study. Int J Physiother Res. 2019; 7(3): 3085-89.

19. Kim BB, Lee JH, Jeong HJ, Cynn HS. Effects of suboccipital release with cranio-cervical flexion exercise on cranio-cervical alignment and extrinsic cervical muscle activity in subjects with forward head posture. J Electromyogr Kinesiol. 2016; 30(3): 31-7.

20. Kim SJ and Lee JH. Effects of sternocleidomastoid muscle and sub-occipital muscle soft tissue release on muscle hardness and pressure pain of the sternocleidomastoid muscle and upper trapezius muscle in smartphone users with latent trigger points. Medicine (Baltimore). 2018; 97(36): 1-6.

21. Tousignant M, Poulin I, Marchand S, Viau A, and Place C. The Modified-Modified Schober Test for range of motion assessment of lumbar flexion in patients with low back pain: A study of criterion validity, intra - and inter-rater reliability and minimum metrically detectable change. Disabil Rehabil. 2005; 27(10): 553-9.

22. Fairbank JC, Pynsent PB. The Oswestry Disability Index. Spine (Phila Pa 1976). 2000; 25(22): 2940-52.
23. Chapman JR, Norvell DC, Hermsmeyer JT et al. Evaluating common outcomes for measuring treatment success for chronic low back pain. Spine (Phila Pa 1976). 2011; 36(21S): S54-S68.

24. Aparicio EQ, Blanco CR, Quirante LB. Immediate effects of the sub-occipital muscle inhibition technique in subjects with short hamstring syndrome. J Manipulative Physiol Ther. 2009; 32(4): 262-9.

25. Moon HJ, Choi KH, Kim DH, Kim HJ, et al. Effect of lumbar stabilization and dynamic lumbar strengthening exercises in patients with chronic low back pain. Ann Rehabil Med. 2013; 37(1): 110-7.

26. Suh JH, Kim H, Jung GP, Ko JY, Ryu JS, Kang H. The effect of lumbar stabilization and walking exercises on chronic low back pain. A randomized controlled trial. Medicine. 2019; 98: e16173.

27. Jeong ED, Kim CY, Kim SM, Lee SJ, Kim HD. Short-term effects of the suboccipital muscle inhibition technique and cranio-cervical flexion exercise on hamstring flexibility, cranio-vertebral angle, and range of motion of the cervical spine in subjects with neck pain: A randomized controlled trial. J Back and Musculoskelet Rehabil. 2018; 31(6): 1025-34.

28. Hack GD, Koritzer RT, Robinson WL, Hallgren RC, Greenman PE. Anatomic relation between th rectus capitis posterior minor muscle and the dura mater. Spine (Phila Pa 1976). 1995; 20(23): 2484-6.

29. Myers TW. Anatomy trains. Edinburgh: Churchill Livingstone, 2005: 97-101. 